\title{
Perfect Order and Its Components: Application for Deliveries of Fast Moving Consumer Goods to Retail Stores
}

\author{
Michal Patak, Lenka Branska, Zuzana Pecinova
}

\author{
University of Pardubice \\ Stavarov 97, 53210 Pardubice, Czech Republic \\ E-mail.michal.patak@upce.cz; lenka.branska@upce.cz; zuzana.pecinova@upce.cz
}

cross $^{\text {ref }}$ http://dx.doi.org/10.5755/j01.ee.31.2.22480

\begin{abstract}
The perfect order concept is traditionally used to measure logistics performance. However, this often brings a wide range of practical problems with it because the conventional assessment of the perfect order from the perspective of the "in-time, in-full and error-free" trinity is no longer viable today. This paper aims to create a novel understanding of the perfect order concept with respect to recent changes in business environment. Based on the primary survey in 132 Czech retail stores, the authors identified the key components that constitute a perfect order fulfilment of fast moving consumer goods to retail stores, namely reliability, collaboration, extra adaptation, ordering, and promotion. Subsequently, it was found that there are differences in the importance of the identified components depending on the retail store type. Promotion and extra adaptation services are more important for stores with consumer chemicals, methods of ordering are more important for small stores or stores with food products and collaboration activities are more important for retail chain stores. The revised definition of the perfect order supports better understanding the customer needs and, thus, could contribute to supply chain performance, especially in the supply chains with fast moving consumer goods.
\end{abstract}

Keywords: Fast Moving Consumer Goods; Logistics Performance; Logistics Service; Order Fulfilment; Perfect Order, Retail.

\section{Introduction}

Logistics performance measurement represents a constant challenge for all businesses. Various measuring approaches exist but virtually all use the perfect order concept as their key metric. According to Christopher (2016) the perfect order is achieved when each of the customer's service requirements are met to the customer's satisfaction. Consequently, a perfect order is calculated by identifying consumer requirements and by measuring the vendor's capability to satisfy those requirements.

The application of the perfect order benchmark as the indicator of the logistics performance is not without its problems. According to Novack \& Thomas (2004) the most fundamental underlying issue is deciding which elements, also referred to hereinafter as components, to include in the perfect order, how to account for the customers' and business's perspective with respect to the individual elements of the performance (meaning the resources invested to achieve the perfect order), what weight to attribute to various elements when evaluating the perfect order, whether some elements of the order may be substituted for others and which qualities of the individual elements should be emphasized when provided to customers in the form of a service. Additional problems also come to arise with respect to the actual measurement of the perfect order (after the end of the monitored period) and in introducing improvements based on the outcome of the perfect order measurement.

Apparently, measuring the logistics performance on the basis of the perfect order indicator still represents a notable challenge. The perfect order concept needs to be developed and its individual elements evolved to produce a truly reliable instrument for the measurement of logistics performance. This paper aims to make a modest contribution to solving one of the outstanding issues mentioned above, namely "which elements to include in the perfect order metric". We are not penetrating terra intacta here, the concept has been used for over two decades. The question we would like to address is whether the conventional assessment of the perfect order from the perspective of the "in-time, in-full and error-free" trinity is still viable today or whether we need to update the concept for the more recent business practice. We particularly refer to the massive integration trend that has affected the traditional supply chain structures, which may also shift our perspective on the perfect order concept. Specifically, the vertical and also the horizontal integration that reflects the needs and requirements of both the end customers and the other links in the supply chain may substantially affect the proportional significance of various logistics services.

To get to the gist, the paper attempts to shift the traditional understanding of the perfect order concept. We proceed based on the assumption that the perfect order consists of pre-transaction, transaction and post-transaction services, and predicate our argument on the idea that the significance of these categories of services is more or less comparable from the customer's viewpoint (or at least that the proportional significance attributed to each does not differ to a substantial degree). In our view, the use of the three traditional elements of the perfect order metric ("in-time, in-full, errorfree") no longer appears sufficient to indicate the quality of customer service. We are not attempting to replace the traditional elements with a new, ad-hoc portfolio of essential services. Instead, we propose using the factor analysis of the significance (materiality) of the services provided to identify 
the fundamental components of the perfect order, specifically the latent factors that influence the perceived significance of the services. The perfect order elements that we derive in this manner should help guide our understanding of the perceived significance of services as provided to individual customers from their perspective as well as help solve the problem of the comparability of the significance of various services.

Based on the reasoning above, the objective of the paper is to find the key components of the perfect order fulfilment of fast moving consumer goods (FMCG) to retail stores with respect to recent changes in business environment.

To fulfil the objective of the paper, primary research was conducted in Czech retail stores with a focus on the evaluation of the importance of logistics services from their point of view. Exploration factor analysis allowed to take into consideration the ascertained importance of all the services by identifying the key components of a perfect order.

The paper is organized as follows. Chapter 1 identifies current approaches to logistics performance measurement available within the perfect order framework and outlines the outcomes of previous research on the significance of logistics services as a basis for the perfect order definition. Chapter 2 introduces primary research goals and methods used in preparing and implementing the retail store survey. Chapter 3 evaluates the importance of logistics services provided to Czech retail stores with respect to FMCG deliveries, and through the factor analysis of the significance of the services provided, identifies the key components of the perfect order. Obtained results are then reviewed in the follow-up discussion that accounts for both the context of the data obtained by previous research and the type of retail stores to which the FMCG are supplied.

\section{Literature Review}

Different scholars in our field propose different approaches to logistics performance measurement and even some of the generally accepted principles have evolved over time. Initially, logistics performance used to be measured by the cost elements of physical distribution, to be replaced later by the benefits of various logistics activities (Novack \& Thomas, 2004). The evaluation metric was then expanded to incorporate the perfect order concept (Novack \& Thomas, 2004) until we ended up with the Supply Chain Operations Reference (SCOR) model, which is currently considered to be the best set of metrics for measurement of supply chain performance (Ainapur et al., 2011). The SCOR model is broadly used to measure logistics performance in a wide range of industrial applications, such as in the construction industry (Persson et al., 2010; Wibowo \& Sholeh, 2015), the food industry (Guritno et al., 2015; Elgazzar et al., 2011; Guritno, 2016; Garcia et al., 2012; Sutopo et al., 2015; AlaHarja \& Helo, 2014), the footwear industry (Sellitto et al., 2015), the textile industry (Nurhasanah et al., 2016), the steel industry (Ainapur et al., 2011; Seifbarghy et al., 2010; Ainapur et al., 2012) or in healthcare and medical services (Jones et al., 2015).

The application of the SCOR model on the evaluation of performance as well as the application of any other multidimensation measurement devices is always fraught with the risk of choosing the correct indicators (Lorentz at al., 2012; Behrouzi \& Wong, 2011; Behrouzi \& Wong,
2013) and weighing their proportional significance (Ainapur et al., 2011; Guritno et al., 2015; Xu Xiao Xia et al., 2007; Wibowo \& Sholeh, 2015; Elgazzar et al., 2011). It is also essential to ensure that the indicators reflect the viewpoint of the customer. The proper combination of the indicators should account for the customer's expectations and most significant requirements regarding the logistics services and their quality, and the customer's satisfaction with the services (Novack \& Thomas, 2004). The most frequently reported metric that sums up all those qualities is what we call the "perfect order".

\section{The Perfect Order Concept}

The perfect order metric traditionally measures the number of on-time, in-full and error-free deliveries (Christopher 2016). Frequently, this basic approach has been modified to reflect different variables. For example, Cook (2001) defined a perfect order as one that contains the right quantity of the right product, delivered on time, damagefree, with an accurate invoice. Gilmor (2009) uncovered a total of 11 different criteria used by businesses to calculate the perfect order. By modifying the definition of the perfect order, some authors adjust the concept to suit their needs, and then apply their understanding to measure logistics performance and to deal with associated problems. A unified (formal) definition does not exist in the business practice (Ganguly, 2013); in some instances, the definition of a perfect order varies even within the same firm (Novack \& Thomas, 2004; Theeranuphattana \& Tang, 2007). At the same time, companies tend to have some kind of understanding as to which services should be included in the definition of the perfect order (Novack \& Thomas, 2004).

The exact quantification of the perfect order may be based on a different quantity of services, but basically, the goal is to identify the percentage of orders completed without any problem, that is to assure compliance with all of the terms of the contract (Lukinskiy \& Lukinskiy, 2017). To maximize the percentage, the company may define the perfect order as a process (Lukinskiy \& Lukinskiy, 2017; Janiesch et al., 2012) and then manage the supply process accordingly in order to improve its own logistics performance.

Other authors also use the perfect order metric in the evaluation of productivity by analysing the performance from the perspective of the customers while also reviewing the resources invested to complete the order, meaning that they include the assessment of the adequacy of the costs associated with the delivery in the evaluation (Eckert, 2007; Ganguly \& Guin, 2013) or the minimum asset levels required (Lorentz at al., 2012). Sometimes the evaluation also takes into consideration achievement of the company's strategic goals. In such instances, the perfect order evaluation also reviews the sources and the destination of the order (Tarasewicz, 2016; Chira \& Musetescu, 2016).

It almost goes without saying that a proper understanding and definition of the term "perfect order" has numerous business benefits. A good definition of the perfect order helps in the evaluation of the business performance of the supplier, and it may be used as a key benchmarking indicator (Janiesch et al., 2012) or for the selection and/or assessment of the business's own suppliers (Janiesch et al., 2012; Kumar et al., 2008; Amer et al., 2010) as well as an 
indicator of the company's ability to integrate material flows at the supply chain level (Elzarka et al., 2013).

\section{The Importance of Logistics Services as a Basis for the Perfect Order Definition}

Perfect order measurement depends on the accurate identification of the portfolio of logistics services to be incorporated in the indicator. The services must be of fundamental importance for the customer, which means that they must act as a major contributor to customer value. As early as in the 1990's, Innis \& La Londe (1994) managed to demonstrate that the importance of logistics services rendered in connection with the delivery generally prevails over the importance of marketing services. Sharma \& Lambert (1994) expanded on their conclusions by establishing that the importance may differ in customers operating in various industry sectors.

The application of the customer services indicators as a measure of logistics performance has been researched in greater detail by Stewart (1995), Fawcett \& Cooper (1998), Gunasekaran et al. (2001), Stock \& Lambert (1992), Innis \& La Londe (1994) and Gunasekaran et al. (2004). In their work, Fawcett \& Cooper (1998) and Gunasekaran et al. (2001) also recommend using the delivery-to-request date, delivery-to-commit date, order fill lead time, flexibility, the customer query time, and post-transaction measures of customer service (for example, timely availability of spares). In other words, they advise incorporating not only the evaluation of selected logistics services and the analysis of their quality, but also to include in the review some additional services and their quality, even if their focus is not primarily on the logistics (as is the case with respect to the provision of spare parts).

In addition, Stock \& Lambert (1992) identified three types of logistics services of utmost importance for customers - accuracy in filling orders, consistent lead times, and the ability to expedite emergency orders in a fast, responsive manner. In addition, they discovered that the five attributes which were not originally included in the surveys, but which were rated as being important, included "information on projected delivery date is provided when order is placed", "information on inventory availability is provided when order is placed", "ability of manufacturer to meet promised delivery date," damage-free shipments", and "length of promised lead times for emergency orders" (Stock \& Lambert 1992). Obviously, their review added information sharing and flexibility to the three traditional criteria ("in-time, in-full, error-free").

Regarding the significance of services in retail stores, Innis \& La Londe (1994) showed in their research that services provided in connection with physical distribution are rated as highly important. They discovered that customer value as significant attributes such as high fill rate, frequency of delivery, and information on inventory availability, projected shipping date, and projected delivery date at the time of order placement (Innis \& La Londe, 1994). Holcomb (1994) also added the important finding that the length of the order cycle tends to be perceived as the most essential attribute.

Gunasekaran et al. (2004) classified logistics services into several groups sorted by their importance. They identified services of high importance (quality of delivered goods, on time delivery of goods, flexibility of service systems to meet customer needs), services of moderate importance (effectiveness of enterprise distribution planning schedule, effectiveness of delivery invoice methods, number of faultless delivery notes invoiced, percentage of urgent deliveries, information richness in carrying out delivery), and services of low importance (percentage of finished goods in transit, delivery reliability performance). Apparently, they account for in their assessment the internal view of the business, which means that they recommend taking into consideration the effectiveness of selected business activities (e.g. the effectiveness of the enterprise distribution planning schedule).

The significance of various logistics services for the customer may also differ depending on the industry. According to Stock \& Lambert (1992), some services are important irrespective of the field or sector, while the significance of other services largely relies on them. Holcomb (1994) identified which of the services are generally essential. She discovered that the length of the order cycle, on-time delivery, and completeness of shipments are consistently the highest ranked customer service delivery attributes across the market segment and order type (Holcomb, 1994). It therefore appears likely that Christopher's (2016) traditional concept of delivery has a universal application.

The critical dimensions of the services that identify the perfect order were also the subject of the inquiry pursued by Fawcett \& Cooper (1998). Their conclusions confirm Christopher's (2016) surmise that the critical dimensions include the dimensions of time, place and damage, to which they also add the dimension of cost. They also highly recommend measuring the perfect order in those dimensions (Fawcett \& Cooper, 1998). Novack \& Thomas (2004) agree and advise pursuing improvements on those very lines. Specifically, improvements should focus on eliminating errors in instruction manuals and other documents, barcoding errors and paperwork errors that arise in the sales process.

The perfect order indicator may also be measured with respect to third-party logistics providers. The basis dimensions of the perfect order in this context are briefly discussed by Bromley (2001). The concept of the perfect order is analysed by Bromely in terms of order entry accuracy, picking accuracy, carrier damages, back orders and pricing accuracy.

In order to arrive at the most accurate formula that could be used to calculate the perfect order indicator, Amer et al. (2010) researched a leading international retail chain. They identified the perfect order as being the combined function of delivery time, quality; quantity delivered, and manifests accuracy. In their opinion, this is the key metric for monitoring the order fulfilment. We subscribe to this view, because it accounts for all of the basic variables of the perfect order as described by the prominent scholars in our field. However, even this approach does not fully take into account recent changes in business environment (customer's pressure on a higher level of collaboration among chain members as well as the use of modern logistics and information technologies in order fulfilment). For this reason we consider further research in this area to be necessary and beneficial. 


\section{Research Objectives and Methods}

The research goal is threefold:

- to identify the importance of logistics services associated with FMCG deliveries to retail stores,

- to identify the key components that constitute a perfect order fulfilment of FMCG to retail stores,

- to identify the differences in the importance of the identified components depending on the retail store type.

To fulfil the goals, the quantitative survey was designed. Based on the literature review outcomes with the help of retail store managers, a portfolio of the logistics services provided in connection with FMCG deliveries was proposed. We included 28 pre-transaction, transaction and post-transaction services in the survey:

- Offering of goods by sales representatives (hereinafter referred to as Sales representatives),

- Provision of promotion materials relating to the products on sale (Promotion materials),

- The possibility to test the products sold (Product testing),

- Provision of training oriented at a knowledge of the products sold (Product training),

- Consultations over supplier plans concerning delivery innovations (Delivery innovations information),

- Ordering of goods via telephone (Telephone ordering),

- Ordering of goods via e-mail (E-mail ordering),

- Ordering of goods using EDI or other standardized forms (EDI ordering),

- The possibility to agree on fixed quantity ordering (Fixed quantity ordering),

- Possibility to agree on fixed period ordering (Fixed period ordering),

- Automatic replenishment (Automatic replenishment),

- Provision of information on stock availability (Stock availability information),

- Provision of order status information (Order status information),

- Supplier flexibility - request for order size modification (Flexible order sizes),

- Supplier flexibility - request for delivery date modification (Flexible delivery times),

- Short delivery times (Short delivery times),

- Delivery of goods right on time (On-time deliveries),

- Delivery of the right goods - type and quantity (In-full deliveries),

- Delivery of goods with error-free supportive documentation (Error-free deliveries),

- Supplier-arranged transport of goods (Arranged Transport),

- Adapting pack sizes to meet retail store requirements (Pack sizes),

- Choice of payment terms and conditions (Payment conditions),

- Expeditious handling of complaints (Complaints),

- Recovery of packaging in which the goods were transported to the retail store (Reverse packaging),

- The possibility to return unsalable goods by reason of incorrect demand estimate (Reverse goods due to forecasts),

- The possibility to return unsalable goods by reason of expired shelf life (Reverse goods due to expirations),
- Supplier cooperation in demand forecasting (Collaborative forecasting),

- Supplier cooperation in planning and replenishment (Collaborative planning and replenishment).

To collect data, we handed out personalised questionnaires in 132 Czech retail stores with FMCG from February to April 2017. We asked the respondents (retail store managers) to evaluate the importance of pre-specified services using a 7-points scale (where $1=$ totally unimportant, 7 = extraordinarily important). A numerical rating scale was preferred over other techniques (pairwise comparisons or ordinal ranking) due to the high number of logistics services in a questionnaire. Thanks to the using of numerical range (not using the range of verbal attitudes) the overall importance of services was evaluated by the arithmetic mean and the median.

In the second phase, the key components of a perfect order were identified through exploratory factor analysis (by using the extraction method of Principal Component Analysis). When extracting factors, we were deciding about the number of factors with respect to Kaiser's criterion (Kaiser, 1960) and the point of inflexion in a scree plot (Cattel, 1966). Interpretability of factors was improved through the orthogonal rotation to ensure uncorrelated factors (Varimax with Kaiser Normalization). With respect to sample size, factors were interpreted by significant factor loadings with a value of 0.5 or higher (Stevens, 2002). To evaluate factor analysis, we used Bartlett's test (to verify whether the correlation matrix is significantly different from an identity matrix), Kaiser-Meyer-Olkin measure of sampling adequacy (KMO) and Cronbach's alpha as a measure of scale reliability.

We realize that the importance of perfect order components (gained factors) could be influenced by different attitudes of purchasing managers belonging to different store types. In the final phase of data analysis, we therefore focused on the differences among retail stores according to their prevailing product range, retail chain affiliation, sales area, and the size of the municipality in which the retail store is located. See the structure of the research sample in Table 1.

Table 1

\section{The Structure of the Research Sample}

\begin{tabular}{|c|c|c|c|}
\hline Characteristics & Category & Frequency & Percent (\%) \\
\hline \multirow[b]{2}{*}{$\begin{array}{l}\text { Prevailing } \\
\text { product range }\end{array}$} & Food products & 69 & 52 \\
\hline & $\begin{array}{l}\text { Consumer } \\
\text { chemicals }\end{array}$ & 63 & 48 \\
\hline \multirow{2}{*}{$\begin{array}{l}\text { Retail chain } \\
\text { affiliation }\end{array}$} & Independent store & 35 & 27 \\
\hline & Retail chain & 97 & 73 \\
\hline \multirow{2}{*}{ Sales area } & $\begin{array}{l}\text { Up to } 400 \text { square } \\
\text { metres }\end{array}$ & 108 & 82 \\
\hline & $\begin{array}{l}\text { Greater than } 400 \\
\text { square metres }\end{array}$ & 24 & 18 \\
\hline \multirow{2}{*}{$\begin{array}{l}\text { Store location } \\
\text { (the size of the } \\
\text { city } \\
\text { municipality) }\end{array}$} & $\begin{array}{l}\text { Up to } 50,000 \\
\text { inhabitants }\end{array}$ & 72 & 55 \\
\hline & $\begin{array}{l}\text { Greater than } \\
50,000 \text { inhabitants }\end{array}$ & 60 & 45 \\
\hline Total & & 132 & 100 \\
\hline
\end{tabular}

We used the arithmetic mean of individual factor scores within groups (retail store type) to analyse the differences. Individual factor scores were calculated as a weighted arithmetic mean of individual importance scores (achieved 
in the survey) using significant factor loadings as weights. Individual factor scores were also standardized (standard normal distribution) for their easier interpretation. In that case, the negative value of standardized factor scores represents a weaker importance, while the positive value represents a stronger importance. The statistical significance of the differences between the groups was verified by ANOVA test at the 0.05 level of significance.

The data were processed using the statistical software package IBM SPSS Statistics (v. 24). Statistically significant differences are appeared in bold in the tables.

\section{Results and Discussion}

\section{The Importance of Logistics Services}

Table 2 depicts the importance of the individual logistics services rendered in FMCG deliveries to retail stores. It follows from means and medians that the respondents regard all of the services at issue as being very important. Traditional "in-full, on-time, and error-free" delivery services may be regarded as being the most important. Highly regarded services allocated a median of 7 (i.e. the highest level of importance) include, apart from traditional services, also short delivery times and fixed period ordering, expeditious handling of complaints, supplier-arranged transport and supplier flexibility from the point of view of delivery time and order size.

Table 2

The Importance of Logistics Services

\begin{tabular}{|l|c|c|}
\hline \multirow{2}{*}{ Logistics service } & \multicolumn{2}{|c|}{ Importance*) } \\
\cline { 2 - 3 } & Mean & Median \\
\hline In-full deliveries & 6.6 & 7 \\
\hline On-time deliveries & 6.5 & 7 \\
\hline Error-free deliveries & 6.5 & 7 \\
\hline Short delivery times & 6.4 & 7 \\
\hline Fixed period ordering & 6.2 & 7 \\
\hline Complaints & 6.1 & 7 \\
\hline Arranged transport & 6.1 & 7 \\
\hline Flexible delivery times & 5.8 & 7 \\
\hline Flexible order sizes & 5.7 & 7 \\
\hline Product testing & 5.5 & 6 \\
\hline Payment conditions & 5.4 & 6 \\
\hline Reverse goods due to forecasts & 5.4 & 6 \\
\hline Reverse goods due to expirations & 5.3 & 6.5 \\
\hline Promotion materials & 5.2 & 5 \\
\hline Pack sizes & 5.0 & 5 \\
\hline Reverse packaging & 5.0 & 5 \\
\hline Stock availability information & 4.8 & 6 \\
\hline EDI ordering & 4.8 & 6 \\
\hline Automatic replenishment & 4.7 & 6 \\
\hline Product training & 4.7 & 5 \\
\hline Sales representatives & 4.7 & 5 \\
\hline E-mail ordering & 4.6 & 5 \\
\hline Fixed quantity ordering & 4.6 & 5 \\
\hline Telephone ordering & 4.4 & 5 \\
\hline Collaborative planning and replenishment & 4.2 & 5 \\
\hline Order status information & 4.2 & 4 \\
\hline Collaborative forecasting & 4.1 & 4 \\
\hline Delivery innovations information & 3.7 & 4 \\
\hline
\end{tabular}

*) Importance was measured on a 7-points scale (where $1=$ totally unimportant, 7 = extraordinarily important).

The portfolio of the most important services identified through our research partially corresponds to the results of earlier research. It clearly confirms that the "in-time, in-full, and error-free" trinity forms part of the most important services provided in connection with a delivery. Nonetheless, also other services of comparable importance were identified. Our research revealed that these include supplier flexibility. The research results of Gunasekaran et al. (2004) confirm this. Not only direct evaluation, but also indirect evaluation confirmed how exceptionally important supplier flexibility really is. Given that the respondents also regard as highly important short delivery times and the expeditious handling of complaints, they in fact need the supplier to be flexible. Unlike the results of earlier research, we have identified a further two services that complement the most important services portfolio; those being the "possibility to agree on fixed period ordering" and "supplier-arranged transport of goods". It is thus apparent that customers very much value deliveries ensuring a certain level of comfort.

Unlike research by Stock \& Lambert (1992), who consider "information on inventory availability" to be a highly important service, our research shows that respondents regard this type of information to be of less importance (mean of 4.8).

An interesting finding is that respondents view services aimed at collaboration or following from collaboration between retail stores and their suppliers to be the least important. Specifically, retail stores perceive it as the least important to cooperate in forecasting, planning, and replenishment and they also do not regard it as too important to track the order status. Following from this finding it may be derived that retail stores and their suppliers have little interest in implementing modern methods of replenishment based on the CPFR model (Collaborative Planning, Forecasting and Replenishment). It may be that such reduced interest may stem from the retail store's want to satisfy its own needs and requirements without actually relying too much on the supplier's involvement and/or aid and support.

\section{The Perfect Order Components}

The first part of research results confirms that a rather large number of elements may make up a perfect order and the given number of elements does not need to be constant, e.g. Gilmor (2009) referred to 11 identified elements. Our research has not identified any exceptionally significant differences between services viewed as being of average importance. The question then arises where should be the borderline defining the portfolio of perfect order services placed. Theoretically speaking, such a borderline should not be laid down at all and each and every one of the services examined should be included in the portfolio in light of the fact that the retail stores evaluated all the services as important. But this does not come across as realistic given the extensive range of these services. A solution may be to reduce the number of services through factor analysis, which at the same time allows for the identification of those latent factors that stand behind the individual services, i.e. the components of a perfect order.

A factor analysis was conducted on the 28 services with orthogonal rotation. The Kaiser-Meyer-Olkin measure verified the sampling adequacy for the analysis (KMO = 0.723). It can be evaluated as "middling" according to Hutchesons \& Sofroniou (1999). Bartlett's test (approx. chi- 
square $=1327.143 ;$ sig. $<0.0005)$ verified that the correlation matrix is significantly different from an identity matrix.

An initial analysis was run to obtain eigenvalues for each factor in the data. Eight factors had eigenvalues over Kaiser's criterion of 1 and their combination explained $66.62 \%$ of the variance. The scree plot was ambiguous and showed inflexions that would justify retaining either solutions with about five factors. We retained five factors because of the small sample size and in an effort to find the simplest and most interpretable solution describing the key components of the perfect order.

Table 3 shows eigenvalues, percentages of explained variance, values of Cronbach's alpha, and the factor loadings after rotation. Achieved values of Cronbach's alpha for subscales are considered to be acceptable values (values between 0.74 and 0.84 ) with respect to number of items on the scale (Cortina, 1993). We also tested the influence of number of gained factors on the values of Cronbach's alpha. When additional factors are considered, values of Cronbach's alpha have increased but relatively slowly.

Table 3

\section{Rotated Component Matrix}

\begin{tabular}{|l|c|c|c|c|c|c|}
\hline & \multicolumn{5}{|c|}{ Component } \\
\cline { 2 - 7 } & $\mathbf{C 1}$ & $\mathbf{C 2}$ & $\mathbf{C 3}$ & $\mathbf{C 4}$ & $\mathbf{C 5}$ \\
\hline Eigenvalues & 3.98 & 3.54 & 2.74 & 2.55 & 2.67 \\
\hline \% of variance & 14.21 & 12.66 & 9.78 & 9.12 & 8.09 \\
\hline Cronbach's alpha & 0.80 & 0.84 & 0.75 & 0.74 & 0.76 \\
\hline Logistics Service & \multicolumn{5}{|c|}{ Factor Loading } \\
\hline In-full deliveries & $\mathbf{0 . 8 8}$ & 0.05 & -0.12 & 0.08 & 0.12 \\
\hline On-time deliveries & $\mathbf{0 . 7 9}$ & 0.04 & -0.08 & 0.01 & 0.16 \\
\hline Error-free deliveries & $\mathbf{0 . 7 5}$ & -0.02 & -0.04 & 0.03 & 0.01 \\
\hline Complaints & $\mathbf{0 . 6 2}$ & 0.11 & 0.14 & -0.01 & -0.10 \\
\hline Short delivery times & $\mathbf{0 . 6 1}$ & 0.07 & 0.29 & -0.11 & 0.02 \\
\hline $\begin{array}{l}\text { Reverse goods due to } \\
\text { forecasts }\end{array}$ & 0.09 & $\mathbf{0 . 8 2}$ & -0.15 & 0.18 & 0.06 \\
\hline $\begin{array}{l}\text { Collaborative planning } \\
\text { and replenishment }\end{array}$ & -0.04 & $\mathbf{0 . 8 0}$ & 0.28 & -0.01 & 0.04 \\
\hline $\begin{array}{l}\text { Reverse goods due to } \\
\text { expirations }\end{array}$ & 0.08 & $\mathbf{0 . 7 6}$ & -0.11 & 0.24 & 0.07 \\
\hline $\begin{array}{l}\text { Collaborative } \\
\text { forecasting }\end{array}$ & -0.02 & $\mathbf{0 . 7 5}$ & 0.29 & 0.08 & 0.06 \\
\hline Reverse packaging & 0.21 & $\mathbf{0 . 5 9}$ & 0.08 & 0.02 & 0.28 \\
\hline $\begin{array}{l}\text { Automatic } \\
\text { replenishment }\end{array}$ & -0.07 & 0.38 & 0.17 & -0.07 & 0.27 \\
\hline $\begin{array}{l}\text { Order status } \\
\text { information }\end{array}$ & 0.01 & 0.05 & $\mathbf{0 . 6 4}$ & -0.09 & 0.18 \\
\hline $\begin{array}{l}\text { Stock availability } \\
\text { information }\end{array}$ & 0.05 & -0.14 & $\mathbf{0 . 6 3}$ & 0.01 & 0.30 \\
\hline Payment conditions & 0.27 & 0.11 & $\mathbf{0 . 5 1}$ & 0.07 & -0.07 \\
\hline $\begin{array}{l}\text { Delivery innovations } \\
\text { information }\end{array}$ & -0.06 & 0.25 & 0.47 & 0.07 & 0.19 \\
\hline Pack sizes & 0.14 & 0.29 & 0.46 & 0.07 & -0.22 \\
\hline Arranged transport & 0.29 & 0.10 & 0.44 & 0.27 & -0.06 \\
\hline E-mail ordering & -0.04 & 0,08 & 0.04 & $\mathbf{0 . 7 3}$ & -0.08 \\
\hline Telephone ordering & 0.11 & 0.05 & 0.07 & $\mathbf{0 . 6 6}$ & -0.30 \\
\hline Fixed quantity ordering & 0.09 & 0.18 & 0.11 & $\mathbf{0 . 6 0}$ & 0.13 \\
\hline Sales representatives & -0.07 & 0.13 & -0.17 & $\mathbf{0 . 6 0}$ & 0.11 \\
\hline Flexible order sizes & 0.26 & 0.02 & 0.24 & 0.43 & -0.01 \\
\hline Fixed period ordering & 0.24 & -0.22 & 0.13 & 0.41 & 0.29 \\
\hline EDI ordering & 0.20 & 0.05 & -0.02 & 0.39 & 0.29 \\
\hline Flexible delivery times & 0.28 & 0.09 & 0.27 & 0.38 & 0.11 \\
\hline Promotion materials & 0.03 & -0.08 & 0.21 & 0.03 & $\mathbf{0 . 6 9}$ \\
\hline Product training & -0.06 & 0.29 & 0.34 & -0.04 & $\mathbf{0 . 5 5}$ \\
\hline Product testing & 0.20 & 0.29 & -0.10 & 0.05 & $\mathbf{0 . 5 5}$ \\
\hline
\end{tabular}

*) Rotation converged in 9 iterations. Factor loadings over 0.5 appear in bold.
The services that cluster on the same factor suggest that key components of the perfect order represent:

- reliability $(\mathrm{C} 1)$,

- collaboration $(\mathrm{C} 2)$,

- extra adaptation (C3),

- ordering (C4),

- promotion (C5).

Component reliability $(\mathrm{C} 1)$ represents in-full, fast, ontime and error-free deliveries, where problems connected with any poor quality delivered are quickly solved. Component collaboration (C2) includes collaboration in what concerns forecasting, planning, and replenishment on the one hand, and collaboration when it comes to returning unsold goods and packaging flow management on the other hand - in fact, collaboration is about promoting cooperation beyond traditional business relations involving the pooling of risks associated with inaccurate forecasts and planning. Component extra adaptation (C3) includes special customisation in that benefits are provided beyond normal trade links. These include order status information, stock availability information and a choice of payment conditions. Component ordering (C4) includes the method of ordering products, specifically the possibility to agree on the ordering and replenishment mechanism. Component promotion (C5) represents marketing benefits directly involved with the increase of knowledge about the products on sale.

\section{The Differences in the Importance of the Perfect Order Components}

Knowledge of perfect order components nevertheless still constitutes an insufficient piece of information. What needs to be understood is whether the individual perfect order components are equally relevant for various customer segments. In the final phase of our statistical analysis, we analysed the difference in the importance of perfect order components, given variously defined groups of retail stores.

Table 4 shows the distinctness in the importance of the perfect order components depending on the prevailing product range within the retail store. Retail stores in the sense of drugstores view extra adaptation $(\mathrm{F}=27.996$; sig. < $0.0005)$ and promotion $(\mathrm{F}=23.497$; sig. $<0.0005)$ as being the significantly more important components. This probably follows from the fact that retail stores specialising in consumer chemical products are just that - specialised stores - and personnel needs to have a sound knowledge of the products on sale and it needs to be able to advise the customer on the most suitable product and promptly sell it to him. And that calls for an on-going enhancement of the knowledge of the individual products, packaging accommodation and the option to track product availability. Contrary thereto, retail stores specialising in food products view ordering $(F=6.413$ sig. $=0.013)$ as being the significantly more important component. Retailers probably need easy access to making an order that the supplier can then flexibly satisfy. 
Table 4

The Component Importance from the Point of View of Prevailing Product Range

\begin{tabular}{|l|c|c|c|c|}
\hline \multirow{2}{*}{ Component } & \multicolumn{2}{|c|}{$\begin{array}{c}\text { Mean score within } \\
\text { groups }\end{array}$} & \multicolumn{2}{c|}{ ANOVA test } \\
\cline { 2 - 5 } & $\begin{array}{c}\text { Food } \\
\text { products }\end{array}$ & $\begin{array}{c}\text { Consumer } \\
\text { chemicals }\end{array}$ & F & Sig. \\
\hline Reliability & -0.115 & 0.126 & 1.942 & 0.166 \\
\hline Collaboration & 0.006 & -0.007 & 0.005 & 0.943 \\
\hline Extra Adaptation & $\mathbf{- 0 . 4 0 1}$ & $\mathbf{0 . 4 3 9}$ & $\mathbf{2 7 . 9 9 6}$ & $<\mathbf{0 . 0 0 0 5}$ \\
\hline Ordering & $\mathbf{0 . 2 0 6}$ & $\mathbf{- 0 . 2 2 6}$ & $\mathbf{6 . 4 1 3}$ & $\mathbf{0 . 0 1 3}$ \\
\hline Promotion & $\mathbf{- 0 . 3 7 2}$ & $\mathbf{0 . 4 0 8}$ & $\mathbf{2 3 . 4 9 7}$ & $<\mathbf{0 . 0 0 0 5}$ \\
\hline
\end{tabular}

*) The negative value represents a weaker importance; the positive value represents a stronger importance.

For independent retail stores, collaboration $(\mathrm{F}=18.131$; sig. $<0.0005)$ is significantly less important component than for retail stores that form part of a retail chain (refer to Table 5). Concluding that collaboration is of a higher importance to retail chains is in itself logical - chain stores collaborate horizontally with other stores of the same retail chain and that is why it is more natural for them to also cultivate vertical cooperation compared to independent retail stores.

Table 5

The Component Importance from the Point of View of Retail Chain Affiliation

\begin{tabular}{|l|c|c|c|c|}
\hline \multirow{2}{*}{ Component } & \multicolumn{2}{|c|}{$\begin{array}{c}\text { Mean score within } \\
\text { groups }\end{array}$} & \multicolumn{2}{c|}{ ANOVA test } \\
\cline { 2 - 5 } & $\begin{array}{c}\text { Independent } \\
\text { stores }\end{array}$ & $\begin{array}{c}\text { Retail } \\
\text { chains }\end{array}$ & $\mathrm{F}$ & Sig. \\
\hline Reliability & -0.115 & 0.042 & 0.632 & 0.428 \\
\hline Collaboration & $\mathbf{- 0 . 5 8 0}$ & $\mathbf{0 . 2 0 9}$ & $\mathbf{1 8 . 1 3 1}$ & $<\mathbf{0 . 0 0 0 5}$ \\
\hline Extra Adaptation & 0.100 & -0.036 & 0.479 & 0.490 \\
\hline Ordering & 0.063 & -0.023 & 0.190 & 0.663 \\
\hline Promotion & -0.125 & 0.045 & 0.742 & 0.391 \\
\hline
\end{tabular}

*) The negative value represents a weaker importance; the positive value represents a stronger importance.

Table 6 demonstrates that ordering $(\mathrm{F}=6.803$; sig. $=$ $0.010)$ is a significantly more important component for small retail stores (with a sales area of up to 400 square metres) than it is for large retail stores (with a sales area greater than 400 square metres). It is rather difficult to identify the causes of such a finding. Small retail stores usually do not dispose of sophisticated computer technology and/or software for ordering products and that is why they most probably prefer to select an ordering and replenishment system of their own.

Table 6

The Component Importance from the Point of View of Sales Area

\begin{tabular}{|l|c|c|c|c|}
\hline \multirow{2}{*}{ Component } & \multicolumn{2}{|c|}{$\begin{array}{c}\text { Mean score within } \\
\text { groups }\end{array}$} & \multicolumn{2}{c|}{ ANOVA test } \\
\cline { 2 - 5 } & $\begin{array}{l}\text { Small } \\
\text { stores }\end{array}$ & $\begin{array}{c}\text { Large } \\
\text { stores }\end{array}$ & $\mathrm{F}$ & Sig. \\
\hline Reliability & -0.003 & 0.013 & 0.005 & 0.946 \\
\hline Collaboration & -0.037 & 0.167 & 0.820 & 0.367 \\
\hline Extra Adaptation & 0.016 & -0.070 & 0.143 & 0.706 \\
\hline Ordering & $\mathbf{0 . 1 0 5}$ & $\mathbf{- 0 . 4 7 1}$ & $\mathbf{6 . 8 0 3}$ & $\mathbf{0 . 0 1 0}$ \\
\hline Promotion & 0.012 & -0.052 & 0.080 & 0.778 \\
\hline
\end{tabular}

*) The negative value represents a weaker importance; the positive value represents a stronger importance.
Finally, the location of the retail store also plays a role (refer to Table 7). Retail stores in large towns (the capital city or a regional town) view collaboration $(\mathrm{F}=11.059$; sig. $=0.001)$ as being significantly more important than retail stores in small towns (up to 50,000 inhabitants).

Table 7

The Component Importance from the Point of View of Store Location

\begin{tabular}{|l|c|c|c|c|}
\hline \multirow{2}{*}{ Component } & \multicolumn{2}{|c|}{$\begin{array}{c}\text { Mean score within } \\
\text { groups*) }\end{array}$} & \multicolumn{2}{c|}{ ANOVA test } \\
\cline { 2 - 5 } & $\begin{array}{c}\text { Cities or } \\
\text { regional } \\
\text { towns }\end{array}$ & $\begin{array}{c}\text { Small } \\
\text { towns }\end{array}$ & $\mathrm{F}$ & Sig. \\
\hline Reliability & 0.020 & -0.024 & 0.062 & 0.804 \\
\hline Collaboration & $\mathbf{- 0 . 2 5 5}$ & $\mathbf{0 . 3 0 6}$ & $\mathbf{1 1 . 0 5 9}$ & $\mathbf{0 . 0 0 1}$ \\
\hline Extra Adaptation & -0.154 & 0.184 & 3.822 & 0.053 \\
\hline Ordering & 0.122 & -0.146 & 2.375 & 0.126 \\
\hline Promotion & -0.144 & 0.173 & 3.339 & 0.070 \\
\hline
\end{tabular}

*) The negative value represents a weaker importance; the positive value represents a stronger importance.

\section{Conclusions}

The perfect order concept constitutes a generally accepted indicator for measuring logistics performance. Selected logistics services provided to customer are used to set this indicator. It generally goes without saying that the services in question must be those most important for the customer, but to this day there is no consensus as to the specific services eligible and as to how many of these services should be included in the evaluation.

The primary research carried out in Czech retail stores uncovered a high level of importance in what regards all of the other services in question. That is why we recommend all services be included in the perfect order, but indirectly through perfect order components as identified by factor analysis. The perfect order components identified are reliability, collaboration, extra adaptation, ordering and promotion. These components help to identify real customer expectations associated with the delivery. In Czech supply chains with fast moving consumer goods, promotion and extra adaptation services are more important for stores with consumer chemicals, used methods of ordering are more important for small stores or stores with food products, and collaboration activities are more important for retail chain stores.

The revised definition of the perfect order aids us in developing our theoretical understanding of this topic whilst assisting managers in satisfying the needs of their customers. With this new approach, they may adjust their existing logistics services to match the customers' requirements, but also, having the enhanced knowledge of the perfect order components, they may present offers to their customers that will satisfy their needs in a more comprehensive manner. This should bring about a radical improvement in their logistics performance and a reinforcement of the close bond between them and their customers.

In conclusion it may be said that the identified form of perfect order components may be generalised for deliveries to retail stores and other markets, but the identified differences in the importance of the components between the various retail segments may be affected by retail characteristics specific to the Czech Republic. It would seem 
appropriate to verify our conclusion by researching the retail network in another European country, preferably with a significantly different business background; that is to say a European country not encumbered by the application of a centrally planned economy. Finally, it must be stressed that by identifying the components that make up a perfect order we not only improve supplier performance, but also at the same time contribute to its evaluation in a novel way. That, however, requires that the carried out research should be built on. We see as a challenge research of the indicators that should be applied to measure supplier performance from the point of view of the individual components of a perfect order.

\section{References}

Ainapur, B., Singh, R. K., \& Vittal, P. R. (2012). Strategic Study on Enhancement of Supply Chain Performance. International Journal of Business Insights \& Transformation, 5(1), 98-106.

Ainapur, B., Singh, R. K., \& Vittal, P. R. (2011). TOC Approach for Supply Chain Performance Enhancement. International Journal of Business Research and Management, 2(4), 163-168.

Ala-Harja, H., \& Helo. P. (2014). Green Supply Chain Decisions - Case-based Performance Analysis from the Food Industry. Transportation Research Part E: Logistics and Transportation Review, 69(C), 97-107. https://doi.org/10. 1016/j.tre.2014.05.015.

Amer, Y., Luong, L., \& Lee, S. (2010). Case Study: Optimizing Order Fulfillment in a Global Retail Supply Chain. International Journal of Production Economics, 127(2), 278-291. https://doi.org/10.1016/j.ijpe.2009.08.020.

Behrouzi, F., \& Wong, K. Y. (2013). An Integrated Stochastic-fuzzy Modeling Approach for Supply Chain Leanness Evaluation. The International Journal of Advanced Manufacturing Technology, 68, 1677-1696. https://doi.org/10. 1007/s00170-013-4966-1.

Behrouzi, F., \& Wong. K. Y. (2011). An Investigation and Identification of Lean Supply Chain Performance Measures in the Automotive SMEs. Scientific Research and Essays, 6(24), 5239-5252. https://doi.org/10.5897/SRE11.1125.

Bromley, P. (2001). A Measure of Logistics Success. Logistics Quarterly, 7(3), 17-18.

Cattel, R. B. (1966). The Scree Test for the Number of Factors. Multivariate Behavioral Research, 1(2), $245-276$. https://doi.org/10.1207/s15327906mbr0102_10

Chira, R., \& Musetescu, A. (2016). The Impact of Customer Service on Logistics. Revista Economica, 68(3), $24-31$.

Christopher, M. (2016). Logistics \& Supply Chain Management. London: Pearson UK.

Cook, J. A. (2001). Measuring Value: Who Should Measure Your Performance? Logistics Management \& Distribution Report, 40(2), 44-48.

Cortina, J. M. (1993). What Is Coefficient Alpha? An Examination of Theory and Applications. Journal of Applied Psychology, 78(1), 98-104. https://doi.org/10.1037/0021-9010.78.1.98

Eckert, S. G. (2007). Inventory Management and Its Effects on Customer Satisfaction. Journal of Business and Public Policy, 1(3), 1-13.

Elgazzar, S., Tipi, N. S., Hubbard, N. J., \& Leach, D. (2011). A SW Application System for Measuring Supply Chain Operations' Performance Using SCOR FAHP Technique. International Proceedings of Economics Development and Research 16, 37-41.

Elzarka, S., Haddad, S., \& Ren, J. (2013). Assessing the Impact of Marketing/Supply Chain Integration on Business Performance Using a Measurement Taxonomy. Proceedings of the 18th International Symposium on Logistics (ISL 2013): Resilient Supply Chains in an Uncertain Environment, 295-304.

Fawcett, S. E., \& Cooper, M. B. (1998). Logistics Performance Measurement and Customer Success. Industrial Marketing Management, 27(4), 341-357. https://doi.org/10.1016/S0019-8501(97)00078-3.

Ganguly, K. (2013). A Case Study Approach for Understanding Inbound Supply Risk Assessment. Decision, 40(1/2), 8597. https://doi.org/10.1007/s40622-013-0012-2.

Ganguly, K. K., \& Guin, K. K. (2013). A Fuzzy AHP Approach for Inbound Supply Rrisk Assessment. Benchmarking: An International Journal, 20(1), 129-146. https://doi.org/10.1108/14635771311299524.

Garcia, F. A., Marchetta, M. G., Camargo, M., Morel, L., \& Forradellas, R. Q. (2012). A Framework for Measuring Logistics Performance in the Wine Industry. International Journal of Production Economics, 135(1), $284-298$. https://doi.org/10.1016/j.ijpe.2011.08.003.

Gilmor, D. (2009). Is The Perfect Order the Perfect Supply Chain Metric? SupplyChainDigest, March 12. http://www.scdigest.com/assets/FirstThoughts/09-03-12.php.

Gunasekaran, A., Patel, C., \& McGaughey,. R. E. (2004). Framework for Supply Chain Performance Measurement. International Journal of Production Economics, 87(3), 333-347. https://doi.org/10.1016/j.ijpe.2003.08.003. 
Gunasekaran, A., Patel, C., \& Tirtiroglu, E. (2001). Performance Measures and Metrics in a Supply Chain environment. International Journal of Operations \& Production Management, 21(1/2), 71-87. https://doi.org/10.1108/01443 570110358468.

Guritno, A. D. (2016). Analysis of Value Added of Fresh Organic Vegetables for The Development Supply Chain Strategy. KnE Life Sciences, 3(3), 133-137. https://doi.org/10.18502/kls.v3i3.400.

Guritno, A. D., Fujianti, R., \& Kusumasari, D. (2015). Assessment of the Supply Chain Factors and Classification of Inventory Management in Suppliers' Level of Fresh Vegetables. Agriculture and Agricultural Science Procedia, 3, 51-55. https://doi.org/10.1016/j.aaspro.2015.01.012.

Holcomb, M. C. (1994). Customer Service Measurement: A Methodology for Increasing Customer Value through Utilization of the Taguchi Strategy. Journal of Business Logistics, 15(1), 29. https://search.proquest.com/docview/ 212652277 ? accountid=17239.

Hutchesons, G., \& Sofroniou, N. (1999). The Multivariate Social Scientist. London: Sage. https://doi.org/10.4135/978 0857028075

Innis, D. E., \& La Londe, B. J. (1994). Customer Service: The Key to Customer Satisfaction, Customer Loyalty, and Market Share. Journal of Business Logistics, 15(1), 1-27. https://search.proquest.com/docview/212597591? accountid=17239.

Janiesch, C., Matzner, M., \& Muller, O. (2012). Beyond Process Monitoring: a Proof-of-concept of Event-driven Business Activity Management. Business Process Management Journal,18(4), 625-643. https://doi.org/10.1108/14637151 211253765.

Jones, E. C., Gupta, S., \& Starr, L. (2015). RFID Implementation and Enterprise Management in the Healthcare Sector. International Journal of Supply Chain Management, 4(3), 32-38.

Kaiser, H. F. (1960). The Application of Electronic Computers to Factor Analysis. Educational and Psychological Measurement, 20(1), 141-151. https://doi.org/10.1177/001316446002000116

Kumar, P., Shankar, R., \& Yadav, S. S. (2008). An Integrated Approach of Analytic Hierarchy Process and Fuzzy Linear Programming for Supplier Selection. International Journal of Operational Research, 3(6), 614-631. https://doi.org/10.504/IJOR. 2008.019729.

Lorentz, H., Toyli, J., Solakivi, T., Halinen, H., \& Ojala, L. (2012). Effects of Geographic Dispersion on Intra-firm Supply Chain Performance. Supply Chain Management: An International Journal,17(6), 611-626. https://doi.org/10.1108/1 3598541211269229.

Lukinskiy, V., \& Lukinskiy, V. (2017). Evaluation of Stock Management Strategies Reliability at Dependent Demand. Procedia Engineering, 178, 53-56. https://doi.org/10.1016/j.proeng.2017.01.060.

Novack, R. A., \& Thomas, D. J. (2004). The Challenges of Implementing the Perfect Order Concept. Transportation Journal, 43(1), 5-16. http://www.jstor.org/stable/20713555.

Nurhasanah, N., Nurcahayanti, W. T., Meliantika, Ripmiatin, E., Qibtiyah, M., \& Wulandari. S. A. (2016). Enhancing Competitiveness of Textile and Clothing Small-medium Industries through Performance Measurement of Material Planning Using SCOR Method. Proceeding of 9th International Seminar on Industrial Engineering and Management. Available from internet: http://digilib.esaunggul.ac.id/proceeding-the-9th-international-seminar-on-industrialengineering-and-management-9259.html.

Persson, F., Bengtsson, J., \& Gustad, O. (2010). Construction Logistics Improvements Using the SCOR Model - Tornet Case. In B.Vallespir \& T. Alix (Ed.), Advances in Production Management Systems. New Challenges, New Approaches (pp. 211-218). Heidelberg: Springer Berlin. https://doi.org/10.1007/978-3-642-16358-6_27

Seifbarghy, M., Mohammad, R., \& Mohsen, S. (2010). Analyzing the supply chain using SCOR Model in a Steel Producing company. Proceedings of 40th International Conference on Computers and Industrial Engineering, 1-6. https://doi.org/10.1109/ICCIE.2010.5668328.

Sellitto, M. A., Pereira, G. M., Borchardt, M., da Silva, R. I., \& Viegas, C. V. (2015). A SCOR-based Model for Supply Chain Performance Measurement: Application in the Footwear Industry. International Journal of Production Research, 53(16), 4917-4926. https://doi.org/10.1080/00207543.2015.1005251.

Sharma, A., \& Lambert, D. M. (1994). Segmentation of Markets Based on Customer Service. International Journal of Physical Distribution \& Logistics Management, 24(4), 50-58. https://doi.org/10.1108/EUM0000000000369.

Stevens, J. P. (2002). Applied Multivariate Statiscics for the Social Sciencies. Hillsdale: Erlbaum.

Stewart, G. (1995). Supply Chain Performance Benchmarking Study Reveals Keys to Supply Chain Excellence. Logistics Information Management, 8(2), 38-44. https://doi.org/10.1016/S0019-8501(97)00078-3.

Stock, J. R., \& Lambert, D. M. (1992). Becoming a "World Class" Company with Logistics Service Quality. The International Journal of Logistics Management, 3(1), 73-81. https://doi.org/10.1108/09574099210804822. 
Michal Patak, Lenka Branska, Zuzana Pecinova. Perfect Order and Its Components: Application for Deliveries of Fast...

Sutopo W., Maryanie, D. I., \& Yuniaristanto, Y. (2015). Evaluation of Valuable Chain in Palm Oil Industry Based on SCOR Model: a Case Study. International Journal of Logistics Systems and Management, 21(2), $229-241$. https://doi.org/10.1504/IJLSM.2015.069383.

Tarasewicz, R. (2016). Integrated Approach to Supply Chain Performance Measurement - Results of the Study on Polish Market. Transportation Research Procedia, 14, 1433-1442. https://doi.org/10.1016/j.trpro.2016.05.216.

Theeranuphattana, A., \& Tang, J. C. S. (2007). A Conceptual Model of Performance Measurement for Supply Chains: Alternative Considerations. Journal of Manufacturing Technology Management,19(1), 125-148. https://doi.org/10.11 08/17410380810843480.

Wibowo, M. A., \& Sholeh, M. N. (2015). The analysis of supply chain performance measurement at construction project. Procedia Engineering, 125(2015), 25-31. https://doi.org/10.1016/j.proeng.2015.11.005.

Xu Xiao Xia, L., Ma, B., \& Lim, R. (2007). AHP Based Supply Chain Performance Measurement System. Proceedings of IEEE Conference on Emerging Technologies and Factory Automation (EFTA 2007), 1308-1315. https://doi.org/10. 1109/EFTA.2007.4416932.

The article has been reviewed.

Received in January 2019; accepted in April 2020. 